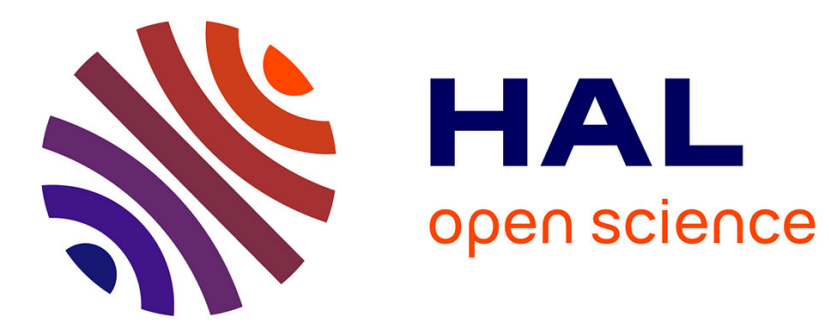

\title{
Identification of heterogeneous elastoplastic materials by Constitutive Equation Gap Method
}

\author{
Tarik Madani, Yann Monerie, Stéphane Pagano, Céline Pélissou, Bertrand
}

Wattrisse

\section{- To cite this version:}

Tarik Madani, Yann Monerie, Stéphane Pagano, Céline Pélissou, Bertrand Wattrisse. Identification of heterogeneous elastoplastic materials by Constitutive Equation Gap Method. iDICs 2016 Conference and Workshop, Nov 2016, Philadelphie, United States. hal-02081150

\section{HAL Id: hal-02081150 \\ https://hal.science/hal-02081150}

Submitted on 27 Mar 2019

HAL is a multi-disciplinary open access archive for the deposit and dissemination of scientific research documents, whether they are published or not. The documents may come from teaching and research institutions in France or abroad, or from public or private research centers.
L'archive ouverte pluridisciplinaire HAL, est destinée au dépôt et à la diffusion de documents scientifiques de niveau recherche, publiés ou non, émanant des établissements d'enseignement et de recherche français ou étrangers, des laboratoires publics ou privés. 


\title{
IDENTIFICATION OF HETEROGENEOUS ELASTOPLASTIC MATERIALS BY CONSTITUTIVE EQUATION GAP METHOD
}

\author{
T. MADANI ${ }^{1,3}$, tarik.madani@umontpellier.fr \\ Y.MONERIE ${ }^{1,3}$, yann.monerie@umontpellier.fr \\ S.PAGANO ${ }^{1,3}$, stephane.pagano@umontpellier.fr \\ C.PeLissou ${ }^{2,3}$, celine.pelissou@irsn.fr
}

B. WATTRISSE ${ }^{1,3}$, bertrand.wattrisse@umontpellier.fr

${ }^{1}$ Université de Montpellier, CNRS, Montpellier, France

${ }^{2}$ Institut de Radioprotection et de Sûreté Nucléaire, PSN/SEMIA, Saint- Paul-Lez-Durance, France

${ }^{3}$ Laboratoire de Micromécanique et Intégrité des Structures, MIST, IRSN-CNRS-Université de Montpellier, France

\begin{abstract}
A strategy for identifying the shape and the parameters of elastoplastic laws in heterogeneous material is proposed here. It allows the local characterization of both mechanical properties and stress fields. This method relies on the constitutive equation gap principles and on the measurement of overall loads and strain fields. These fields are obtained by the numerical differentiation of displacement fields measured by Digital Image Correlation. The identification method is based on the iterative minimization of an energy norm involving the secant elastoplastic tensor.
\end{abstract}

We propose here to characterize the robustness of the method and its stability (to noise, initial parameters and mesh) on numerical data sets obtained on numerically-deformed images. Finally, we illustrate the ability of the method to identify the local material properties of a heterogeneous material on real experimental data.

Keywords: Digital Image Correlation, Identification, Constitutive Equation Gap, Elastoplasticity

\section{Introduction}

Optical measurement techniques applied in the field of Experimental Mechanics have improved significantly in the last decades. Thanks to the large amount of information given by full-field measurement techniques, it is now possible to tackle complex identification problems such as strongly localized phenomena (Lüders bands, crack propagation ...). Mechanical properties are generally identified from overall loading data and kinematic fields (obtained by Digital Image Correlation, interferometric techniques, grid methods, etc.). The Finite-Element Updating Method is probably the most widespread identification method, as it allows identifying very different physical properties. Specific methods, adapted to the identification of mechanical behaviors were also proposed. A general overview over existing identification techniques can be found in [1]. The Constitutive 
Equation Gap Method (CEGM) method was chosen because of its adaptability to a wide range of behaviors but also for its ability to identify heterogeneous behaviors.

The method presented here is an extension of the one proposed in [2]. It relies on the analytic expression of the local elastoplastic secant stiffness tensor $\underline{\underline{B^{s}}}$. For a linear kinematic model, the tensor $\underline{\underline{B}}$ can be expressed directly as a function of the material properties (e.g. for J2-plasticity: yield stress $\sigma_{0}$ and hardening coefficient $h$ ) and of the loading (through the plastic increment $\Delta \gamma$ ). After briefly presenting the method, we illustrate its performances on numerical and experimental data.

\section{Identification methodology}

We propose a method to identify the parameters of an elastoplastic constitutive law in a 2D (plane stress) framework for a kinematic multi-linear hardening associated with a Von Mises criterion. The CEGM is based on the minimization of a functional expressing the gap in the constitutive equation. In its simplest form (small strain hypothesis, equilibrium, and linear elastic constitutive behavior) the cost-function reads:

$$
F_{C E G M}\left(\overrightarrow{u^{c}}, \underline{\underline{B^{s}}}(p)\right)=\frac{1}{2} \int_{\Omega}\left[\underline{\varepsilon}\left(\overrightarrow{u^{c}}\right)-\underline{\varepsilon}\left(\overrightarrow{u^{m}}\right)\right]: \underline{\underline{B^{s}}}(p):\left[\underline{\varepsilon}\left(\overrightarrow{u^{c}}\right)-\underline{\varepsilon}\left(\overrightarrow{u^{m}}\right)\right] d \Omega
$$

where vector $p$ regroups the material parameters, $\overrightarrow{u^{m}}$ is a measured displacement field, $\overrightarrow{u^{c}}$ a displacement field compatible with the local and global equilibrium of the studied domain $\Omega$. For an elastoplastic material and at a given time step $n$, the secant stiffness tensor $B_{n}^{s}$ reads [3]:

$$
\underline{\underline{B_{n}^{S}}}(p)=\left[\underline{\underline{B}}^{e^{-1}}+\frac{\Delta \gamma(n)}{1+\frac{2}{3} h \Delta \gamma(n)} \underline{\underline{P}}\right]^{-1}
$$

where $\underline{\underline{B^{e}}}$ is the elastic tensor (depending, for a cubic material, on the three elastic constants: e.g. Young modulus $E$, shear modulus $G$, and Poisson ratio $v$ ), $\Delta \gamma(n)$ is the plastic multiplier increment at time step $n$ and $\underline{\underline{P}}$ is a constant mapping matrix.

The secant tensor depends on five material constants $p=\left\{E, G, v, \sigma_{0}, h\right\}$ (three for elasticity and two for plasticity). The identification procedure consists in minimizing functional $F_{C E G M}$ over all admissible displacements $\overrightarrow{u^{c}}$ (such as the derived stress field satisfies the equilibrium equations, the constitutive equations and the global equilibrium conditions) and all admissible material parameters (such as $\underline{B_{n}^{S}}$ is positive-definite). Thanks to the properties of convexity of functional $F_{C E G M}$, the minimization can be performed in two consecutive steps: first with respect to its first argument (to determine a displacement field associated with a statically-admissible stress fields ) and then with respect to the secant stiffness tensor (to identify the material parameters). In order to increase the robustness of the procedure, the elastic parameters are determined separately from the plastic one on purely elastic load steps. The procedure is controlled through an optimization algorithm. The iterative procedure is started with an initial set of parameter chosen arbitrarily. The procedure is stopped using a convergence criterion on the norm of the secant tensor, and the optimal material parameters are obtained.

\section{Identification of heterogeneous mechanical properties}

The method is firstly assessed on numerical data obtained on a finite-element simulation of a heterogeneous elastoplastic polycrystal with four phases. The geometry and the material parameters used for the direct computation are given in Figure 1.a. Supposing that the phase distribution is known and introducing the displacement field and the overall loads in the identification procedure, the material parameters distribution (see Figure 1.b) and the stress field (see Figure 1.c) are identified. In this example (isotropic J2-plasticity with linear kinematic hardening), the material parameters of each phase are: $E^{R}=$ $210 \mathrm{GPa}, v^{R}=0.3, \sigma_{0}^{R}=300 \mathrm{MPa}, h^{R}=2 \mathrm{GPa}, \quad E^{O}=180 \mathrm{GPa}, v^{O}=0.25, \sigma_{0}^{O}=300 \mathrm{MPa}, h^{O}=2.5 \mathrm{GPa}, \quad E^{G}=$ $100 \mathrm{GPa}, v^{G}=0.15, \sigma_{0}^{G}=300 \mathrm{MPa}, h^{G}=1 \mathrm{GPa}, E^{Y}=150 \mathrm{GPa}, v^{Y}=0.2, \sigma_{0}^{Y}=300 \mathrm{MPa}, h^{Y}=1.5 \mathrm{GPa}$. Figure 2 shows some identified quantities (hardening modulus $h$ and axial stress $\sigma_{y y}{ }^{c}$ ). The identification, performed here without superimposed noise, is quite consistent with the imposed fields. 


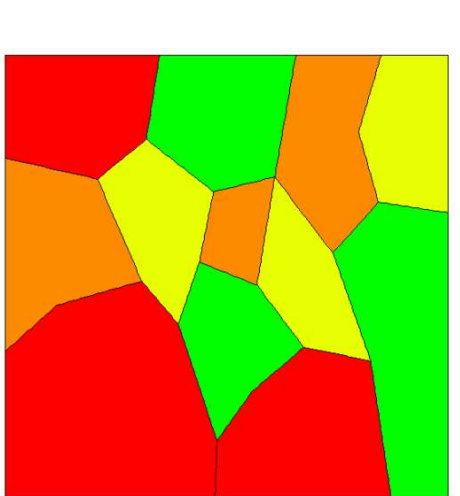

(a)

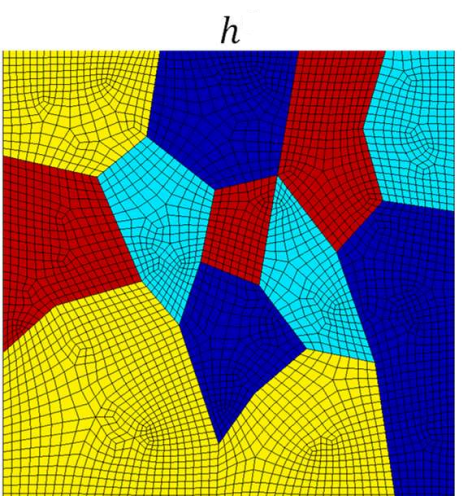

(b)

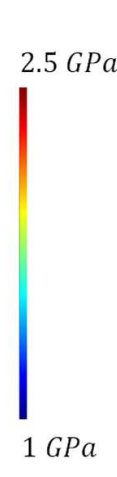

$1 \mathrm{GPa}$

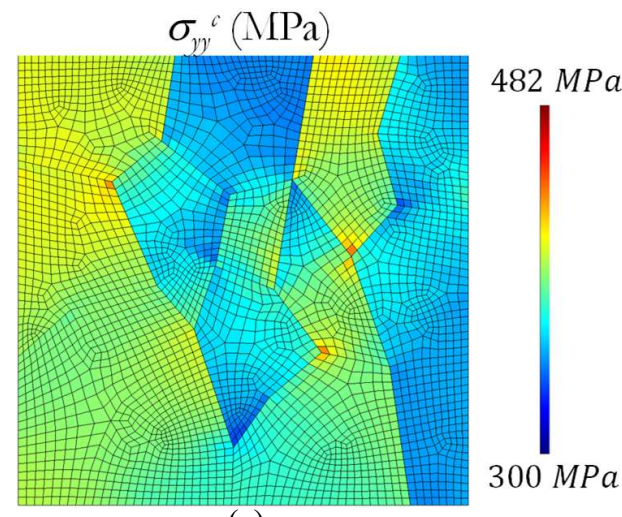

(c)

Figure 1.a - Geometry of the polycrystalline specimen composed of four phases (R, O, Y, and G) and 12 grains, $1 . b-$ identified hardening modulus and 1.c - identified axial stress field component

The method has been applied on experimental data obtained on a heterogeneous material with a known heterogeneity: a Dual Phase steel (DP600) tensile specimen machined in a trapezoidal sample having undergone a known pre-hardening. The method correctly identifies the heterogeneous behavior of the material as can be seen in Figure 2 showing the "theoretical" yield stress associated with the known pre-hardening (Figure 2.a) and the identified one (Figure 2.b).

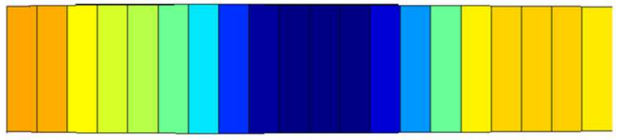

(a)

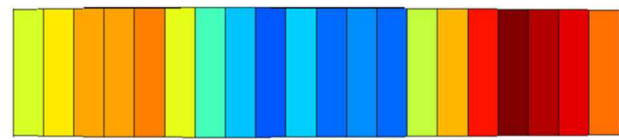

(b)

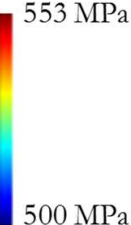

Figure 2 - Identified fields of yield stress $\sigma_{0}, 2 . \mathrm{a}$ - theoretical values and 2.b - identified values

\section{Conclusions}

We illustrate the use of the CEGM to identify the parameters of an elastoplastic behavior from full-field measurements. Here we identify mechanical stresses and a distribution of elastic and plastic coefficients. The originality of this work resides in its ability to tackle heterogeneous stress fields associated with either heterogeneous materials or complex structures for elastic or plastic materials. The method is developed for multi-linear hardening behaviors. It requires only an estimation of the elastic properties. The choice of the initial guess was shown not to affect the identified values. The proposed procedure was checked on the basis of numerically-obtained displacement fields given by a FE simulation. Results of the study show the ability of the method to deal with strongly heterogeneous situations. Gaussian white noise was also superimposed to the numerical data in order to assess the robustness of the method with respect to noise. This method was successfully applied on an experimental situation associated with a heterogeneous material.

\section{References}

[1] S. Avril, M. Bonnet, A.S. Bretelle, M. Grediac, F. Hild, P. Ienny, F. Latourte, D. Lemosse, S. Pagano, E. Pagnacco, (2008) Overview of identification methods of mechanical parameters based on full-field measurements. Experimental Mechanics 48, 381-402.

[2] F. Latourte, A. Chrysochoos, S. Pagano, B. Wattrisse, (2008) Elastoplastic behavior identification for heterogeneous loadings and materials, Experimental Mechanics 48 435-449.

[3] JC. Simo, TJR. Hughes, (1998). Computational inelasticity. Springer. 